\title{
26
}

\section{Information Systems Project Manager's Critical Success Factors: In-house Versus Outsourced Development}

\author{
Hugo Rehesaar and Andrew Rose \\ School of Information Systems, University of New South Wales, 2052, Australia. \\ Information Systems Branch, Pacific Power, Sydney, 2000, Australia.
}

\begin{abstract}
Software quality is measured in many ways; in this paper we look at Client Acceptance.

In order to aid the process of managing and achieving client acceptance, a pilot study has been undertaken to identify the project manager's critical success factors (CSF) for achieving client acceptance. With the increase in outsourcing it is also of interest to determine whether the critical success factors might be different for software developed in-house when compared with that developed by a third party. A previous study (Rehesaar and Rose [1]) found differences in client acceptance criteria between in-house and outsourced projects and these criteria are used here.

This study found that for similar client acceptance criteria there are no differences between in-house and outsourced project manager's critical success factors. However, significant differences were found in the specified critical success factors for different client acceptance criteria. Most notably, eleven of the eighteen critical success factors were applicable to only one client acceptance criterion each.

Therefore, project managers who are changing from in-house to outsourced development or vice versa must be aware that they should apply a different set of critical success factors based on the different set of client acceptance criteria they must satisfy.
\end{abstract}

Keyword Codes: K.6.1; D.2.9; K.6.m

Keywords: project management, critical success factors; project success; outsourcing

\section{INTRODUCTION}

To facilitate the acceptance of a project by the client, project managers must at least ensure that their clients' acceptance criteria (CAC) are satisfied. The method proposed to ensure that these client acceptance criteria are satisfied is the critical success factor (CSF) method. The critical success factor method, when applied to client acceptance criteria, identifies the limited number of areas in which results, if they are satisfactory, will allow satisfaction of the criteria that a client will use to evaluate a completed software product for acceptance.

The client acceptance criteria to be used in this study come from previous research by the authors (Rehesaar and Rose [1]). In that study, a list of probable client acceptance criteria was formulated from an analysis of information systems project success literature. This list was provided to a sample of software development clients to determine the criteria they use to evaluate a software product. The result was two lists of top five client acceptance criteria, one each for in-house and outsourced development.

Using this list of client acceptance criteria, a sample of software development project managers was asked to identify the critical success factors for the satisfaction of each of the client's acceptance criteria. The results are critical success factors for each of the client acceptance criteria. Because a 
difference was found in client acceptance criteria for in-house and outsourced development, this distinction in project management is also investigated.

\section{CRITICAL SUCCESS FACTORS}

Critical success factors (CSFs) are, for any business, the limited number of areas in which results, if they are satisfactory, will ensure successfully competitive performance in an organisation. If results in these areas are not adequate, the organisation's outcomes will be less than desirable.

The critical success factor concept was first discussed in management literature by Ronald Daniel [2]. He stated that "in reporting internal data, a company's information system must be discriminating and selective. It should focus on 'success factors'. In most industries these are usually three to six factors that determine success; these key jobs that must be done exceedingly well for a company to be successful".

Boynton and Zmud [3] found that the CSF method has attracted considerable attention as a method of supporting both MIS planning and requirements analysis. The research into project critical success factors has been directed towards project implementation success rather than client acceptance criteria, for example, Lasden [4], Wall [5], Wolff [6], Norko [7] (anecdotal), Holt [8], Keller [9], Curtis [10] (single case studies), Rockart [11] (multiple case study), Cleland and King [12], Baker, Fisher and Murphy [13] (normative).

Ashley, Lurie and Jaselskis [14] in research into determinants of construction project success found that a strong relationship existed between the following critical success factors and success measures: planning effort - functionality; project manager's technical capability and technical uncertainty - end user satisfaction; projects manager's administrative capabilities - cost; legal political environment follow-up work, leading the way to further work on linking success criteria to specific critical success factors.

\section{RESEARCH AIMS}

a) To investigate the effect of in-house versus outsourced development on project manager's critical success factors.

b) To investigate the effect of client's acceptance criteria on project manager's critical success factors.

\section{RESEARCH SETTING AND SAMPLE.}

The questionnaires were mailed to fifty project managers, representing ten organisations in Sydney, Australia. Both private and public sectors were represented. Five organisations used in-house developers and five were third party suppliers of outsourcing. Only in-house developers with a charge back in place were chosen so as to not introduce payment/non-payment for services as a variable. Follow up phone interviews were conducted where the completed questionnaires were difficult to interpret accurately.

\section{RESEARCH PROCEDURES}

The aim of the data collection was to obtain a list of critical success factors for each client acceptance criterion, relevant to in-house and outsourced development organisation types.

The subject project managers were provided with the list of client acceptance criteria for their organisation types sourced from previous research by the authors (Rehesaar and Rose, 1994). They 
were asked to list CSFs for satisfying each of the CACs. A minimum of three and a maximum of six critical success factors were suggested for each CAC. Additional space was provided for explanation of each CSF to minimise misinterpretation.

The client acceptance criteria for in-house development are shown in Table 1.

The client acceptance criteria for outsourced development are shown in Table 2.

Table 1 .

Client Acceptance Criteria and Critical Success Factors for In-house Project Managers

Client Acceptance Criteria Critical Success Factors

1. Delivery of the completed product with all the functional requirements specified initially or with mutually agreed upon changes.

2. Completion of the product with the agreed performance level.

3. The completed product satisfies all the screen, report and data entry requirements specified initially or with mutually agreed upon changes.

4. The completed product is likely to directly benefit the intended users: either through increasing efficiency or effectiveness.

5. The completed product works as it was intended to work.
1. Project Plan/Schedule

2. Requirements/Specifications

3. Involvement of Key Personnel

4. Monitoring and Feedback

5. Project and Change Control

6. System Testing

7. Delivery of Product

1. Performance Criteria

2. Resources Available for Performance Measurement (including personnel, methodologies and tools)

3. Performance Testing

1. Project Plan/Schedule

2. Requirements/Specifications

3. System Design

4. Involvement of Key Personnel

5. Monitoring and Feedback

6. Project and Change Control

1. Project Support

2. Cost/Benefit Analysis

3. Involvement of Key Personnel

4. Training

1. Requirements/Specifications

2. Involvement of Key Personnel

3. Monitoring and Feedback

4. Project and Change Control

5. System Testing

\section{THE SAMPLE}

The experience of the respondent in software development and project management was used to evaluate the validity of individual questionnaire results. The project managers from both the internal development and the outsourcing organisations had at least six years experience in software 
development and at least one year in project management. No questionnaires were rejected based on the respondent's lack of experience. The response rate for questionnaires from the in-house developers was $47 \%$ and from the outsourcing developers was $40 \%$.

Table 2: Client Acceptance Criteria and Critical Success Factors for Outsourced Project Managers

Client Acceptance Criteria $\quad$ Critical Success Factors

1. Acceptance of the completed product by staff for whom it is intended.

2. Delivery of the completed product with all the functional requirements specified initially or with mutually agreed upon changes.

3. The completed product works as it was intended to work.

4. The completed product is likely to represent a definite improvement in performance over the way the activity used to be performed.

5. The completed product is reliable.
1. Requirements/Specifications
2. Involvement of Key Personnel
3. Ergonomic Considerations
4. Monitoring and Feedback
5. Project and Change Control

1. Project Plan/Schedule

2. Requirements/Specifications

3. Involvement of Key Personnel

4. Monitoring and Feedback

5. Project and Change Control

6. System Testing

7. Delivery of Product

1. Requirements/Specifications

2. Involvement of Key Personnel

3. Monitoring and Feedback

4. System Testing

1. Project Mission

2. Cost/Benefit Analysis

3. Involvement of Key Personnel

4. Monitoring and Feedback

1. Requirements/Specifications

2. Resources

3. Reliability Measurement

4. Monitoring and Feedback

5. System Testing

\section{RESULTS}

\subsection{Effect of In-house versus Outsourced Development}

Comparison of the two lists of clients acceptance criteria yielded two criteria which were the same for both in-house and outsourced development. The critical success factors for them were compared.

(a) Criterion: 'Delivery of the completed product with all the functional requirements specified initially or with mutually agreed upon changes.'

All seven of the CSFs suggested by the in-house project managers were identical with those of the outsourced developer. The critical success factors are: (1) Project plan/schedule (2) Requirements 
/specifications (3) Involvement of key personnel (4) Monitoring and feedback (5) Project and change control (6) System testing (7) Delivery of product.

(b) Criterion: 'The completed product works as it was intended to work.'

For this criterion, the four factors specified by outsourced project managers were shared by inhouse project managers, of whom $30 \%$ also added 'Project and change control' as a fifth factor. The four shared factors are: (1) Requirements/specifications (2) Involvement of key personnel (3) Monitoring and feedback (4) System testing.

\subsection{Effect of Client Acceptance Criteria on Critical Success Factors}

In total, 18 critical success factors were identified for the 8 discrete client acceptance criteria.

Of these only two factors (4 and 5) applied to six criteria, of which five were the same; one (13) applied to five criteria; one (8) applied to four; two (10 and 17) applied to three; and one (1) applied to two criteria. The remaining eleven factors were applicable to only one criterion each.

\section{DISCUSSION AND FURTHER RESEARCH}

Two client acceptance criteria, from the lists of top five criteria, were common to both in-house and outsourced development. For each of these criteria, the critical success factors were the same for both in-house and outsourced project managers, except for one CSF which was specified by less than one third of the in-house project managers.

This suggests that for the same criteria there is no perceived difference in the prioritisation of the work of in-house versus outsourced project managers. That is, the critical success factors are transferable from one environment to the other for similar client acceptance criteria. This is surprising, since the clients in the two environments exhibited marked differences in how they determined whether or not to accept the software product.

Further research is warranted to identify reasons for this disparity and also to determine if the tasks undertaken by the two sets of projects managers to achieve the same critical success factors are different.

The eight discrete client acceptance criteria demonstrated a wide scattering of critical success factors, sharing a total of eighteen CSFs. Only two critical success factors were applicable to six criteria, with eleven factors applicable to only one criterion each. Whilst two criteria (in-house 1 and 3) shared five factors, no pattern emerged linking criteria with sets of factors or vice versa. It is noted that these two criteria were very similar; both referred to satisfaction of requirements.

The results show a strong link between specific client acceptance criteria and their respective critical success factors, with no two criteria sharing critical success factors. Thus project managers will need to be aware of the acceptance criteria employed by their clients and must customise their own critical success factors accordingly if they are to maximise their chances of success.

Despite this strong one-to-one link, three critical success factors were prominent, namely 'monitoring and feedback', 'involvement of key personnel' (both with six criteria) and 'requirements/specification' (with five criteria).

Analysing the data as a whole, showed that one critical success factor 'monitoring and feedback' was applicable to all five of the outsourcing criteria and only three of the in-house criteria. Removing the two common criteria, results in a three to one split. While this suggests a possible influence on critical success factors by in-house versus outsourced in the area of importance ranking of critical success factors, the amount of data in this study does not allow for any more than speculation. Further research with a larger data set may prove interesting.

Whereas no direct link has been established between critical success factors and the in-house versus outsourced environment, the very fact that the critical success factors were strongly linked to the client 
acceptance criteria does provide an indirect influence on CSF choice, in that the CACs are different between in-house and outsourced development. Hence the project manager in the in-house environment will be working to a markedly different set of critical success factors than the outsourced project manager.

\section{CONCLUSION}

Previous research on differences between in-house and outsourced development concentrated on the criteria clients use for accepting a software product. It found significant differences in the criteria used. In this study on critical success factors for the same set of client acceptance criteria, no such difference between in-house and outsourcing was found. Significant differences were found in the specified critical success factors for different client acceptance criteria. Most notably, eleven of the eighteen critical success factors were applicable to only one client acceptance criterion each.

Nevertheless, project managers who are changing from in-house to outsourced development or vice versa must be aware that they should apply a different set of critical success factors based on the different set of client acceptance criteria they must satisfy.

\section{REFERENCES}

1. Rehesaar, H. and Rose, A. "The Effect of the Client/Developer Environment on Software Acceptance Criteria", ITRC Working Paper 94/14, University of New South Wales, Australia, March, 1994.

2. Daniel, R.D., "Management Information Crisis", Harvard Business Review, September-October 1961, pp. 111-121

3. Boynton, A.C. and Zmud, R.W., "An Assessment of Critical Success Factors", Sloan Management Review, Summer 1984, pp. 7-27

4. Lasden, M., "Effective Project Management", Computer and Communication Decisions, March 1980, pp. $49-59$

5. Wall, W.C., "Ten Proverbs for Project Control", Research Management, March 1982, pp. 26-29

6. Wolff, M.F., "Rules of Thumb for Project Management", Research Management, Vol. 27, JulyAugust 1984, pp. 11-13

7. Norko, W.A., "Steps in Successful Project Management", Journal of Systems Project Management, September 1986, pp. 36-38

8. Holt, L., "Project Management Principles Succeed at ICI", Industrial Management \& Data Systems, March-April 1983, pp. 4-9

9. Keller, R.T. "Predictors of the Performance of Project Groups in R\&D Organisations", Academy of Management Joumal, Vol. 29, 1986, pp. 715-726

10. Curtis, W., Krasner, H. and Iscoe, N., "A field study of the software design for large systems", Communications of the ACM, Vol. 31, No. 11, November 1988, pp. 1268-1287

11. Rockart, J.F., "The Changing Role of the Information Systems Executive: A Critical Success Factor Perspective", Sloan Management Review, Fall 1982, pp. 3-13

12. Cleland, D.I. and King, W.R., Systems Analysis and Project Management, McGraw- Hill, New York, 1983

13. Baker, B.N., Murphy, D.C. and Fisher, D., "Factors Affecting Project Success", in Project Management Handbook, Cleland D.I. and King W.R., Van Nostrand Reinhold, New York, 1983, pp. 669-685

14. Ashley, A.B., Lurie, C.S. and Jaselskis, E.J., "Determinants of Construction Project Success", Project Management Journal, Vol. 18, No. 2, June 1987, pp. 69-79 